\title{
Platelets and platelet extracellular vesicles in hemostasis and sepsis
}

\author{
Elizabeth W J Kerris, ${ }^{1,2}$ Claire Hoptay (1) , ${ }^{2}$ Thais Calderon, ${ }^{3}$ Robert J Freishtat ${ }^{2,4}$
}

${ }^{1}$ Division of Critical Care Medicine, Children's National Hospital, Washington, DC, USA ${ }^{2}$ Center for Genetic Medicine Research, Children's National Hospital, Washington, DC, USA ${ }^{3}$ Department of Medical Education, University of Rochester School of Medicine and Dentistry, Rochester, New York, USA ${ }^{4}$ Division of Emergency Medicine, Children's National Hospital, Washington, DC, USA

\section{Correspondence to} Dr Claire Hoptay, Center for Genetic Medicine Research, Children's National Hospital, Washington, DC 20010, USA;

CHoptay@childrensnational. org

EWJK and $\mathrm{CH}$ contributed equally.

EWJK and $\mathrm{CH}$ are joint first authors.

Accepted 23 November 2019

Published Online First

15 December 2019

\section{Check for updates}

(C) American Federation for Medical Research 2020. No commercial re-use. See rights and permissions. Published by BMJ.

To cite: Kerris EWJ, Hoptay C, Calderon T, et al. J Investig Med 2020;68:813-820.

\begin{abstract}
Platelets, cell fragments traditionally thought of as important only for hemostasis, substantially and dynamically contribute to the immune system's response to infection. In addition, there is increasing evidence that externally active platelet entities, including platelet granules and platelet extracellular vesicles (PEVs), play a role not only in hemostasis, but also in inflammatory actions previously ascribed to platelets themselves. Given the functions of platelets and PEVs during inflammation and infection, their role in sepsis is being investigated. Sepsis is a condition marked by the dysregulation of the body's normal activation of the immune system in response to a pathogen. The mechanisms for controlling infection locally become detrimental to the host if they are applied systemically. Similar to cells traditionally ascribed to the immune system, including neutrophils, lymphocytes, and macrophages, platelets are instrumental in helping a host clear an infection, but are also implicated in the uncontrolled amplification of the immune response that leads to sepsis. Clearly, the function of platelets is more complicated than its simple structure and primary role in hemostasis initially suggest. This review provides an overview of platelet and platelet extracellular vesicle structure and function, highlighting the complex role platelets and PEVs play in the body in the context of infection and sepsis.
\end{abstract}

\section{PLATELETS IN HEMOSTASIS}

Platelets are small anuclear cell fragments that circulate in the blood. Circulating platelets are discoid-shaped and smooth, with an uncompromising cytoskeleton that maintains its integrity even under the high fluid shear forces produced by blood flow. ${ }^{1-3}$ The traditional role of platelets is to detect and rapidly respond to blood vessel injury. ${ }^{145}$ On injury, vascular endothelial cells and connective tissue cells release soluble factors that attract and activate platelets. ${ }^{15}$ Platelets quickly arrive at and attach to the site of injury. Attachment leads to changes in platelet shape; they flatten, elongate, and extend small projections. ${ }^{1267}$ These adaptive changes in structure enhance the activated platelets' ability to attach, spread, and recruit additional platelets to the site so that a platelet plug forms and covers the damaged area. ${ }^{15}$
Signal transduction during platelet activation Platelet structural changes rely on the signal transduction that occurs when platelets are activated. Platelets activate after exposure to soluble platelet agonists. ${ }^{1578}$ Agonists are released from damaged cells, already activated platelets, or other inflammatory cells. ${ }^{1}{ }^{2}$ 5-11 Common agonists include collagen, ADP, von Willebrand factor (vWF), thrombin, fibrinogen, fibronectin, serotonin, and platelet-activating factor. ${ }^{1578}$ When an agonist binds to a receptor on the platelet surface, alterations in intracellular signaling promote cytoskeletal rearrangements and increased platelet receptor affinity that is necessary for platelet aggregation and the formation of thrombi. ${ }^{5}{ }^{12-15}$ Intracellular signaling occurs in three stages: (1) early platelet activation signaling, (2) intermediate common signaling events, and (3) integrin signaling. ${ }^{1578}$

The interaction of an agonist with a platelet adhesion receptor initiates early platelet activation signaling. ${ }^{1578}$ Depending on the bound receptor, early platelet activation signaling occurs through the Scr family kinases, phosphoinositide 3-kinases, immunoreceptor tyrosine-based activation motif, ${ }^{156}$ or through heterotrimeric G proteins. ${ }^{15}$ Regardless of the type of receptor involved in early activation signaling, all signal transduction pathways converge during the second stage of signaling. ${ }^{15}$ During this intermediate stage, Phospholipase C is activated, ${ }^{15}$ leading to increased calcium and activated protein kinase C. ${ }^{15}$ Both increased calcium and PKC are required for granule secretion from activated platelets and calcium is necessary for the cytoskeletal rearrangements that change the activated platelet shape. ${ }^{135}$

The final stage of platelet activation signaling, integrin signaling, can be inside-out or outside-in. Inside-out signaling changes the ligand-binding function of cell adhesion proteins known as integrins. ${ }^{1}{ }^{13}{ }^{15-17}$ In the resting platelet, integrins are present on the cell surface in the low-affinity state but switch to the high-affinity state when the platelet is activated. ${ }^{5} 8121315$ 17-19 This alteration in the affinity of integrins enhances the aggregatory function of activated platelets, allowing them to bind to other platelets and cells at the site of injury. ${ }^{512131517}$ Outside-in signaling is initiated solely when the agonist-bound receptor is the integrin GPIIb/IIIa.5 121315172021 When an agonist binds to GPIIb/IIIa, changes in the 


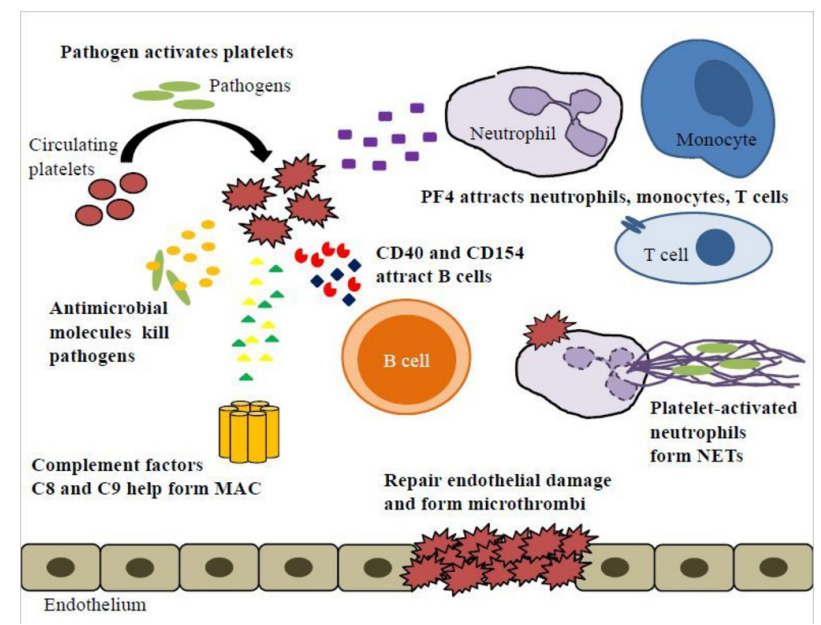

Figure 1 Platelet function in infection. When platelets interact with pathogens, such as bacteria, they activate and degranulate. Contents released during degranulation promote death of the pathogen and activation of the innate and adaptive immune systems. Antimicrobial molecules, including reactive oxygen species, microbicidal proteins, and kinocidins, can directly kill pathogens. Platelets also release, among other factors, CD40 and CD154 to attract B cells, complement factors C8 and C9 to ultimately form part of the membrane attack complex (MAC), and platelet factor 4 (PF4) to attract monocytes, T cells, and neutrophils to carry out their traditional roles as players in the immune system. Neutrophils that are directly activated by platelets and/ or endotoxin form neutrophil extracellular traps (NETs), web-like structures created when neutrophils release their granular and nuclear contents into the extracellular space. NETs help trap pathogens to minimize their spread from the primary site of infection. Spread of pathogens is also minimized when platelets bind to damaged endothelium and, when combined with fibrin, form microthrombi to create a physical barrier.

intracellular domains of the integrin allow a $G$ protein subunit to bind. $5121315-17$ 20-22 This amplifies the platelet's responses to G-coupled-protein receptor (GPCR) agonists,

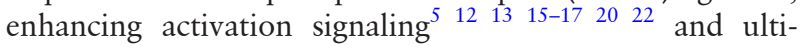
mately promoting cytoskeletal rearrangement and activated platelet function. ${ }^{51213161720}$

\section{PLATELETS AS AN IMMUNE 'CELL' IN INFECTION AND SEPSIS}

In addition to their well-established role in hemostasis, ${ }^{14-6}$ activated platelets participate in the host immune system in a variety of ways, including direct interaction with an invading pathogen, mediation of the inflammatory response via the complement and innate immune systems, and communication with leukocytes and the adaptive immune system (figure 1). ${ }^{6} 1023-29$ Platelets also play an important role in the immune response when the normal activation of the immune system is dysregulated, as in sepsis. ${ }^{30}$

\section{Platelet interactions with invading pathogens}

Because platelets are abundant in the blood and highly sensitive to changes in their environment, they frequently interact with invading pathogens directly and before the activation of the innate immune response. ${ }^{123-28}$ Platelets have been shown to directly phagocytose bacteria, fungi, viruses, and protozoa. ${ }^{6} 102325-28$ Microorganisms are internalized into vacuoles when platelets are activated via the FC $\gamma$ RIIa receptor. ${ }^{123}$ 25-28 Similar to primary immune cells, platelets also express toll-like receptors (TLRs) that allow them to respond to pathogen-associated molecular patterns (PAMPs). ${ }^{25}$ In addition to TLRs, platelets use the GPIIb/IIIa receptor to form fibrin bridges to adhere to microbes and the Fc receptor FcyRIIa to bind to IgG immune complexes to form platelet-pathogen aggregates. ${ }^{25}$

Platelets activated by invading pathogens also undergo degranulation of antimicrobial molecules, including reactive oxygen species (ROS), platelet microbicidal proteins, and chemokines with microbicidal activity, referred to as kinocidins. ${ }^{125-29}$ Platelet microbicidal proteins are small, cationic polypeptides that can kill pathogens, including fungi, via direct disruption of the cell membrane through voltagedependent channels. ${ }^{12531}$ Platelet microbicidal proteins are stored in platelet granules and in the cytoplasm of platelets. ${ }^{25}$

The effectiveness of antimicrobial molecules expressed by platelets is enhanced by the formation of microthrombi. Microthrombi form through the interaction of activated platelets and the vascular endothelium. As innate immune cells are activated, tissue factor (TF) is released into the circulation from monocytes and macrophages ${ }^{32}$ and the coagulation pathway is initiated. This results in the formation of fibrin, which forms a clot when it interacts with platelets at the primary site of infection. ${ }^{32-37}$ The resulting matrix of fibrin and platelets provides a physical barrier to the spread of infection and creates a concentrated area of platelet antimicrobial molecules.

Neutrophil extracellular traps (NETs) are another mechanism by which the immune system tries to maintain a pathogen at the primary site of infection. NETs form when neutrophils bind to endotoxin-exposed platelets or endotoxin alone. ${ }^{32-34} 38$ Under these conditions, neutrophils release their granular and nuclear components into the extracellular space. ${ }^{32-3438}$ A web-like structure is formed by DNA and proteins, trapping bacteria. ${ }^{32-34} 38$ In this way, NETs serve to limit the spread of pathogens from the initial site of infection and kill the invading pathogen. ${ }^{32-34} 38$

\section{Platelet mediation of the innate immune response}

Platelets further contribute to the host's defense by enhancing and activating components of the immune system, including the complement system. ${ }^{12325-28}$ As part of the innate immune system, the complement system is primarily responsible for the direct lysis and opsonization of pathogens for phagocytosis, recruitment of immune cells to the site of infection, and activation of the adaptive immune system. ${ }^{24}$ The complement receptor $\mathrm{C} 1 \mathrm{q}$ is expressed on activated platelets and facilitates the activation of the classic complement pathway by binding the complement protein C1q. ${ }^{24}$ Activated platelets increase expression of $\mathrm{C} 3 \mathrm{a}$ and $\mathrm{C} 5 \mathrm{a}$ receptors, which bind their respective anaphylatoxins, increasing vascular permeability and allowing for the translocation of immune cells from the vasculature to the active site of infection. ${ }^{24}$

Platelets also contain terminal complement factors C8 and C9, which are released on activation of the platelet. ${ }^{2425}$ After their release, C8 and C9 combine with the activated $\mathrm{C} 5 \mathrm{~b}$, $\mathrm{C} 6$, and $\mathrm{C} 7$ to form the C5b-C9 complex, also known as 
the membrane attack complex (MAC). ${ }^{1243536}$ The complex causes cell lysis through the formation of transmembrane channels. ${ }^{1243536}$ MAC also induces vascular endothelium to release TF and $\mathrm{vWF}$, which are strong initiators of the coagulation cascade. The activation of coagulation leads to microthrombi formation, as previously discussed, and the eventual activation and degranulation of platelets. ${ }^{12435} 36$ Thus, a positive feedback loop exists between the complement system and platelets, where platelets perpetuate the complement system and the complement system activates additional platelets. This enhances the elimination of pathogens, but also predisposes the host to thrombosis.

Activated platelets also release chemoattractants, such as platelet factor 4 (PF4), which attract innate immune cells like neutrophils and monocytes to the site of infection. ${ }^{1} 23$ 25-27 Further, platelets potentiate the effect of neutrophils, important first responders in innate immunity. The direct interaction of platelets and neutrophils is primarily mediated through the binding of P-selectin on the surface of activated platelets with P-selectin glycoprotein ligand-1 (PSGL-1). ${ }^{25} 35$ These platelet-bound neutrophils release antimicrobial proteins and lysozymes and show increased respiratory burst, leading to enhanced phagocytosis, bacterial clearance, and degranulation. ${ }^{135} 37$

\section{Platelet mediated enhancement of the adaptive immune system}

Platelets interact with the adaptive immune system by recruiting and activating T cells and B cells. ${ }^{125-2735}$ Platelets attract $\mathrm{T}$ cells to the site of infection through PF4. ${ }^{125-2736}$ They also express co-stimulatory proteins, which induce differentiation, cytokine production, and activation of $\mathrm{T}$ cells. Additionally, platelets process antigens and present them to $\mathrm{T}$ cells via major histocompatibility complex class I molecules. ${ }^{125-2735}$ Platelets directly activate B cells via the release of soluble CD40 and CD154 ligands, leading to proliferation, differentiation, isotype switching, and memory B cell generation. ${ }^{125-273539}$ In a study by Sprague et al, when platelets from wild-type mice were transfused to CD154 deficient mice during a viral infection, there was a significant increase in circulating virus-specific IgG levels, providing evidence of a link between platelets and the adaptive immune system. ${ }^{40}$

\section{Platelets in sepsis}

Platelets contribute to the pathology of sepsis. Activated platelets and increased coagulation lead to disseminated intravascular coagulation (DIC) and clots in the microvasculature, which can lead to cell death and organ dysfunction. ${ }^{41-50}$ Indeed, platelets accumulate in the microvasculature of many of the commonly failing apoptotic end organs in sepsis, such as the lungs, liver, and spleen, limiting adequate blood flow and drainage to and from these organs. ${ }^{31}{ }^{51-53}$ In sepsis, platelets that have been activated by thrombin or lipopolysaccharide (LPS) express increased amounts of transcript-1 (TLT-1) receptor. ${ }^{48}$ TLT-1 has been shown to facilitate platelet aggregation, therefore augmenting clot formation and promoting DIC.

Platelet-neutrophil interactions also contribute to complications in sepsis. As discussed, endotoxin-activated platelets activate neutrophils to release NETs. This enhances bacterial clearance, which benefits the host; however, host endothelial cells are also damaged in this process and NET formation can lead to liver damage in vivo. ${ }^{32} 343854$ Additionally, neutrophil-platelet aggregates release thromboxane A2 (TXA2), an arachidonic acid metabolite that activates endothelial cells via $G$ protein-coupled thromboxane receptors. Receptor activation leads to integrin activation, platelet aggregation, and increased vascular permeability. ${ }^{37}$ The activation of the pulmonary vascular endothelium by TXA2 is known to be integral in the development of acute lung injury (ALI) associated with sepsis. ${ }^{37}$ Blocking plateletneutrophil aggregation by blocking P-selectin not only decreases circulating levels of TXA2, but in a sepsis-induced murine model of ALI, improves gas exchange and leads to prolonged survival. ${ }^{37}$

Although platelets are anuclear, they do contain a large messenger RNA (mRNA) reservoir and can regulate the translation of their transciptome based on external activating conditions, including sepsis. ${ }^{15-57}$ Specifically, genes related to cell adhesion, chemotaxis, and inflammatory and immune response are differentially expressed in septic platelets. ${ }^{58}$ The cell death-inducing enzyme granzyme B, a serine protease, is an example of a selectively transcribed protein. ${ }^{58}$ Granzyme B induces programmed cell death by proteolytic cleavage of key substrates in target cells ${ }^{59-65}$ and its mRNA is upregulated in platelets of septic patients, suggesting that platelets could be cytotoxic in sepsis. ${ }^{5866} 67$ The mechanism by which septic platelets release granzyme B remains unclear; there are multiple externally active platelet entities that could transport the protein to the target cell.

\section{EXTERNALLY ACTIVE PLATELET ENTITIES-PLATELET GRANULES AND EXTRACELLULAR VESICLES}

In addition to direct interactions, platelets communicate with other cells indirectly through the release of externally active entities, such as granules and extracellular vesicles. Platelet granules are intracellular vesicles that fuse with the plasma membrane to release their contents on activation, while platelet extracellular vesicles (PEVs) are membranebound entities that are released into the extracellular space on platelet activation (figure 2). ${ }^{68-70}$

\section{Platelet granules}

Granule exocytosis from activated platelets helps with the control of endothelial damage, as highlighted by the fact that deficiencies in granule secretion result in bleeding defects. ${ }^{51-74}$ The three main types of platelet granules are: alpha granules, dense granules, and lysosomes. ${ }^{171} 73$ Platelets have approximately 40 to 80 alpha granules per platelet, ranging from $200 \mathrm{~nm}$ to $500 \mathrm{~nm}$ in diameter. ${ }^{171} 7576$ Alpha granules contain large proteins and molecules, like growth factors and chemokines. ${ }^{171}{ }^{75-77}$ Dense granules are ten times less abundant than alpha granules and are smaller. They are identified by the presence of electron-dense spherical bodies within the granule. ${ }^{1717378}$ Dense granules contain smaller molecules such as ADP, ATP, calcium, magnesium, and serotonin. ${ }^{17178}$ Lysosomal granules are the least common type of granule within platelets, with only a few lysosomes per platelet. ${ }^{171}$ Lysosomal granules contain lysosome-associated membrane proteins, acid hydrolases, and cathepsins. ${ }^{171}$ While 


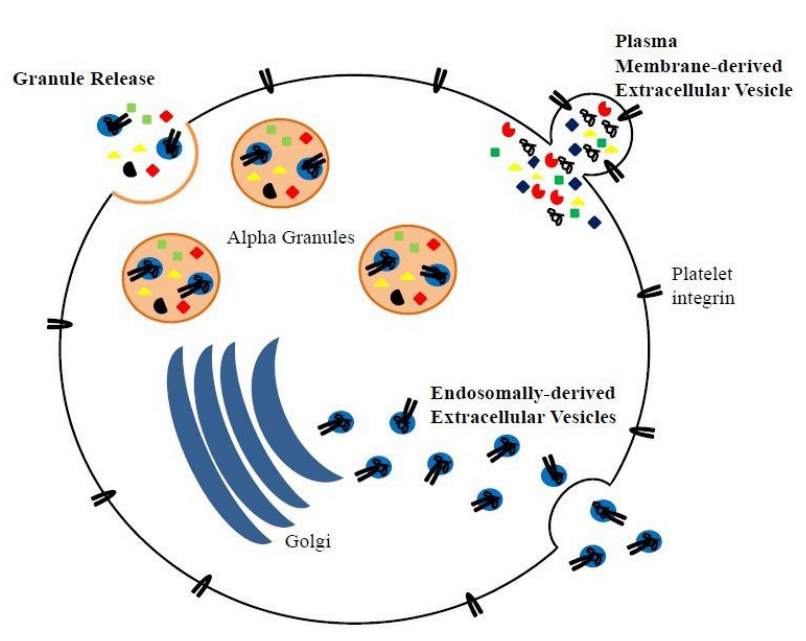

Figure 2 Release of externally active platelet entitiesplatelet granules and extracellular vesicles. Platelet granules are intracellular vesicles that fuse with the plasma membrane to release their contents. Alpha granules, the most abundant type of platelet granule, contain large proteins and molecules and can also contain endosomally-derived PEVs. Endosomally-derived PEVs are the smaller of the two types of PEV and contain variable, nonrandom proteins, mRNA, and miRNA. Plasma membrane-derived PEVs, the second type of PEV, are usually larger than those that are endosomally-derived and they bud off of the plasma membrane. They generally contain protein cargo, including functional platelet receptors, multiple kinds of RNA, and even cell organelles. PEVs often share the same antigens as the parent platelet. mRNA, messenger RNA; miRNA, microRNA; PEVs, platelet extracellular vesicles.

their role is not fully understood, they may play a role in clot remodeling and further platelet activation. ${ }^{1}$

\section{Platelet Extracellular Vesicles}

As previously mentioned, PEVs are membrane-bound entities that are released into the intracellular space on activation of the parent platelet. PEVs are abundant in circulation, representing the majority of extracellular vesicles in the blood. ${ }^{79}$ Extracellular vesicles can be further divided into two major groups: plasma membrane-derived microvesicles and extracellular vesicles of endosomal origin, commonly referred to as exosomes. ${ }^{70} 80-82$ Previously, extracellular vesicles were also differentiated based on size, with the larger, plasma membrane-derived 'microparticles' classified as ranging from $100 \mathrm{~nm}$ to $1000 \mathrm{~nm}$ in diameter, compared with the smaller endosomally-derived 'exosomes' at $40 \mathrm{~nm}$ to $100 \mathrm{~nm}$ in diameter. ${ }^{7080818384}$ Given an inconsistent use of terms in the literature and difficulty in demonstrating specific biogenesis pathways, the International Society for Extracellular Vesicles (ISEV) has recently updated their position on nomenclature. ${ }^{82}$ Instead of using terms such as 'microvesicles', 'exosomes', or 'microparticles', the ISEV endorses the use of the term 'extracellular vesicles' (EV), which can further be described based on size, biochemical composition, and cell of origin. ${ }^{82}$

Platelets release EVs when stimulated by physiological agonists and mediators, such as chemokines, apoptosis, or increased sheer stress. ${ }^{68-70}$ The type of PEV and its contents differ based on the stimuli to which the platelet is exposed. ${ }^{8385-89}$ EVs contain membrane and cytosolic proteins, including fully functional receptors, circular RNA (circRNA), long non-coding RNA (lncRNA), microRNA (miRNA), mRNA, and even encapsulated cellular organelles. ${ }^{85} 8688-90$

\section{Formation of PEVs}

On activation of the platelet, plasma membrane-derived PEVs bud off from the plasma membrane, thus sharing the same antigens as their parent platelet, such as CD41 and CD62p. ${ }^{7083}$ Given their larger size, plasma membranederived PEVs are more likely to contain protein cargo and they express and transfer functional receptors from platelet membranes to other cell types. ${ }^{80} 8391$

PEVs of endosomal origin are generally smaller than the plasma membrane-derived PEVs. ${ }^{80} 83$ Endosomally-derived PEVs are released when multi-vesicular bodies fuse with the platelet plasma membrane. ${ }^{70} 8492$ They are often stored in alpha granules and are released when the granules fuse with the plasma membrane. ${ }^{7083}$ Similar to plasma membranederived PEVs, the cargo of endosome-origin PEVs is variable, non-random, and can include proteins, mRNA, and miRNA. Although the contents of endosomally-derived EVs can be specific to the parent cell, their cargo does not necessarily reflect the contents of the cell from which they were released. For example, endosomally-derived EVs from certain cancer cells contain increased amounts of proteins, mRNA, and miRNA specific to increasing angiogenesis, cell cycle disruption, and immune suppression, thus supporting tumor spread and proliferation. ${ }^{93}$ Given this finding in cancer cell EVs, it is possible that PEVs contain plateletspecific cargo and/or cargo not typically found in platelets.

\section{PEVS IN HEMOSTASIS}

PEVs are integral to the regulation of the coagulation system with both procoagulation and anticoagulation properties. The coagulation capacity of PEVs is estimated between 50 to 100 times that of platelets alone. They carry the prothrombotic proteins annexin- $\mathrm{V}$, factor $\mathrm{X}$, and prothrombin. ${ }^{808994-96}$ The increased coagulation capacity of PEVs is due, in part, to an increase in surface area exposing phosphatidylserine, a negatively charged molecule typically found on the intracellular surface of the platelet plasma membrane, which is exposed on the surface of PEVs. ${ }^{89} 9596$ In the resting state, the enzyme flippase acts to maintain aminophospholipids, specifically phosphatidylserine, on the inner leaflet of the platelet membrane. ${ }^{95}$ In the activated state, flippase activity decreases and floppase activity increases, leading to an imbalance of phosphatidylserine on the outer surface of the platelet membrane prior to PEV formation. ${ }^{95}$ By facilitating the interaction between factor $\mathrm{Va}$ and factor $\mathrm{X}$, the phosphatidylserine on PEVs provides the basis for the prothrombinase complex, leading to an increase in thrombin production. ${ }^{89} 9597$

Healthy individuals' PEVs also express highly concentrated CD41 on their surface, which generates small amounts of thrombin via TF and factor VII independent pathways. ${ }^{98}$ These quantities of thrombin in turn activate protein $\mathrm{C}$, a natural anticoagulant, implying that PEVs may not only be procoagulants, but are also involved in the regulation of coagulation. ${ }^{98}$ 


\section{PEVS IN INFECTION AND SEPSIS}

Similar to platelets, PEVs contribute to the activation of host immune cells by attracting leukocytes to areas of pathogen invasion, facilitating leukocyte-to-leukocyte interactions, and inducing the release of specific cytokines. ${ }^{81}{ }^{99-101}$ In fact, some of the proinflammatory actions traditionally ascribed to platelets may actually be due to PEVs. For example, the inflammatory reaction seen in some cases of platelet transfusion is likely mediated by PEVs. ${ }^{81}{ }^{101}$ PEVs contribute to inflammation in infection through direct recruitment of leukocytes, including $\mathrm{T}$ cells, B cells, and monocytes, via chemokine release and facilitate the interaction between monocytes and endothelial cells by binding P-selectin and PSGL1. ${ }^{102}$ PEVs can upregulate the expression of cyclooxygenase-2, which is the first step in converting arachidonic acid into prostacyclin, causing vasodilation and allowing for an increase in inflammatory cells reaching the site of infection. ${ }^{103}$

As previously mentioned, PEVs' surface markers and their contents vary based on the platelet-activating stimulus. LPS and staphylococcal superantigen-like protein (SSL) are both PAMPs that directly stimulate PEV formation when co-incubated with platelets from healthy subjects, via activation of platelet TLRs. ${ }^{86104}$ Although a specific fungal stimulant has not been identified, sepsis secondary to fungal infections appears to trigger a PEV release with differential surface markers compared with sepsis triggered by bacteria. ${ }^{105}$

LPS stimulates platelets via the TLR4 pathway, leading to c-Jun N-terminal kinase and Akt activation, as it would in nucleated cells, resulting in increased IL- $1 \beta$ in secreted PEVs. ${ }^{104}$ The released IL-1ß induces the expression of vascular cell adhesion protein 1 on endothelial cells, which promotes the binding of leukocytes to the endothelium. ${ }^{104}$

PEVs released in response to SSL5, a Staphylococcus aureus specific antigen, bind to monocytes and lead to a dose-dependent increase in the release of proinflammatory cytokines IL- $1 \beta$ and tumor necrosis factor- $\alpha .{ }^{86}$ SSL5 binds to the platelet membrane receptor glycoproteins GPIba, GPIIb/IIIa, or GPVI to stimulate the release of PEVs. These PEVs in turn bind to and stimulate CD14+ CD16+ monocytes via the P-selectin-PSGL1 and CD40L-CD40 interactions and activation of the NFkB inflammatory pathway. ${ }^{86}$

In addition to being proinflammatory, PEVs released in response to Neiserria meningitidis also express increased amounts of TF on their surface, contributing to the sepsisassociated increase in coagulation. ${ }^{106}$ The activation of platelets in N. meningitidis infection occurs indirectly through the activation of the complement system by the bacteria. Specifically, C5a is associated with an increase in both platelet-associated and PEV-associated TF. Blocking C5 decreases PEV-associated TF expression and reduces TF-dependent procoagulant activity in coagulation assays. ${ }^{106}$

In viral infections, the PEV count is found to be elevated and contributes to the activation of the host's immune system. ${ }^{91} 107108$ In immunized hosts exposed to H1N1, platelets are stimulated to release PEVs both through the formation of thrombin and by the binding of Fc $\gamma$ RIIA. ${ }^{107}$

PEVs also contribute to the propagation of the virus itself. In patients with HIV, PEVs appear to facilitate entry of HIV into target cells through C-X-C chemokine receptor type 4 (CXCR4). ${ }^{91} \mathrm{HIV}$ requires the cell surface antigen
CD4 and a chemokine receptor, either CXCR4 or C-C chemokine receptor type 5 , to enter its target cell. While all of these receptors are present on cells of hematopoietic lineage, specifically lymphoblasts, HIV has also been shown to infect CXCR4 negative cells such as endothelial cells, astrocytes, and cardiomyocytes. Rozmyslowicz et al demonstrated that PEVs can transfer CXCR4, a common receptor on platelets, to CXCR4 negative cells, making them vulnerable to infection with HIV. ${ }^{91}$

In Dengue virus infections, PEVs have not only been shown to be predictive of clinical outcomes, but appear to heavily contribute to the pathogenicity of virus. ${ }^{108-110}$ Platelets are activated to release PEVs directly by Dengue virus via the tyrosine-kinase receptor CLEC-2. PEVs, in turn, activate neutrophils and macrophages through the CLEC5A receptor, inducing NET formation and the release proinflammatory cytokines. ${ }^{108}$ Sung et al found that blocking the effect of PEVs on leukocytes in a mouse model of Dengue increased survival from $30 \%$ to $90 \%$, implicating PEVs in the severe virulence of the disease. ${ }^{108}$

The release of PEVs and their contents in sepsis is not only influenced by the activating stimulus, but can also be affected by host platelet receptors. Children with a GPVIa receptor haplotype had a two-fold increase in circulating PEVs compared with those with GPVIb receptor haplotype in a study of children with sepsis. ${ }^{111}$ The number of PEVs was found to be higher in children with GPVIa receptor and these individuals were also more likely to present with severe features of septic shock, including significant organ failure, compared with those with the GPVIb haplotype. ${ }^{111}$ In addition to contributing to our knowledge of an individual's personal response to an infection, these findings further highlight the role of PEVs as mediator of the inflammatory response to infection.

\section{PEVs as predictive markers}

There has been some investigation into the use of PEVs as a predictor of illness and illness severity in sepsis. The number of PEVs appear to be overall lower in sepsis nonsurvivors and in those with DIC; however this effect is mitigated when PEVs are adjusted for overall platelet count. ${ }^{112}$ Conversely, Boscolo et al found that the PEV to platelet ratio was higher in septic patients that required longer support with vasoactives, mechanical ventilation, and those that developed DIC. ${ }^{113}$ This difference is noted at the time of diagnosis and persists during the course of the illness. ${ }^{113}$

\section{Direct organ dysfunction secondary to small PEVs in sepsis}

Though the smaller PEVs remain understudied compared with larger PEVs, there is evidence that they contribute to the proliferation of inflammation and organ dysfunction in sepsis. ${ }^{114-116}$ The evidence to date suggests small PEVs are involved in myocardial dysfunction and endothelial cell apoptosis, prominent features of sepsis.

In sepsis, vascular endothelial and smooth muscle cell apoptosis is mediated by the generation of ROS through the nicotinamide adenine dinucleotide phosphate (NADPH) oxidase pathway. ${ }^{117}$ Janiszewski et al demonstrated a predominance of small PEVs, compared with small EVs of other inflammatory cell origin (monocytes, granulocytes, 
and lymphocytes) in a study of adults with early sepsis. ${ }^{114}$ Further, PEVs obtained from septic patients not only contain two cytochrome subunits of the NADPH oxidase, but are also present at twice the concentration in PEVs of septic patients compared with healthy controls. ${ }^{114}$ Incubation of endothelial cells and vascular smooth muscles cells with these PEVs induces enhanced spontaneous superoxide generation and significantly increases the rate of apoptosis of those cells in vitro. This suggests an important role for small PEVs in the vascular dysfunction seen in sepsis via a redox signaling pathway. ${ }^{114} 115$

PEVs also depress the function of cardiac myocytes in sepsis, possibly contributing to low cardiac output, a hallmark of septic shock. ${ }^{116}$ Rabbit hearts exposed to PEVs of septic patients show signs of myocardial dysfunction based on a decrease in myocardial contractility. Myocardial cells exposed to PEVs of septic patients demonstrated a higher level of nitrate and nitric oxide, providing a possible pathway of the observed myocardial dysfunction. ${ }^{116}$

\section{CONCLUSION}

Considering their simple structure as anuclear cell fragments, platelets and their extracellular entities play a complex and important role in regulating basic homeostatic and inflammatory functions. Directly and indirectly, through PEVs, platelets contribute to the activation and regulation of coagulation and inflammation in the body. Beyond the 'sticky cell fragments' necessary for clot formation, our understanding of platelets has evolved to include them as immune 'cells'. Further, the role of the platelet in the regulation of both hemostasis and inflammation in the healthy state and dysregulation in the disease state contribute to our overall knowledge of the pathogenesis of disease.

Contributors Each author participated in the literature search, review of the literature, creation of the figures, writing of the manuscript and has approved the manuscript as submitted. EWJK and CH contributed equally to this manuscript as co-first authors.

Funding EWJK is currently receiving support through a Ruth L. Kirschstein National Research Service Award (NRSA) Institutional Research Training Grant awarded to the Children's Research Institute Hematology Training Program by the National Heart, Lung and Blood Institute (NHLBI) of the National Institutes of Health (5T32HL110841-07).

Competing interests None declared.

Patient consent for publication Not required.

Provenance and peer review Commissioned; externally peer reviewed.

ORCID iD

Claire Hoptay http://orcid.org/0000-0002-1463-2215

\section{REFERENCES}

1 Michelson AD. Platelets. Amsterdam: Academic Press/ Elsevier, 2007.

2 Cimmino G, Golino P. Platelet biology and receptor pathways. J Cardiovasc Transl Res 2013:6:299-309.

3 Poulter NS, Thomas SG. Cytoskeletal regulation of platelet formation: coordination of F-actin and microtubules. Int J Biochem Cell Biol 2015;66:69-74.

4 Thon JN, Italiano JE. Platelet formation. Semin Hematol 2010;47:220-6.

5 Li Z, Delaney MK, O'Brien KA, et al. Signaling during platelet adhesion and activation. Arterioscler Thromb Vasc Biol 2010;30:2341-9.

6 Vieira-de-Abreu A, Campbell RA, Weyrich AS, et al. Platelets: versatile effector cells in hemostasis, inflammation, and the immune continuum. Semin Immunopathol 2012;34:5-30.

7 Kamath S, Blann AD, Lip GY. Platelet activation: assessment and quantification. Eur Heart J 2001;22:1561-71.
8 Joo S-J. Mechanisms of platelet activation and integrin $\alpha$ ll $\beta 3$. Korean Circ J 2012;42:295-301.

9 Semple JW, Freedman J. Platelets and innate immunity. Cell Mol Life Sci 2010;67:499-511.

10 Herter JM, Rossaint J, Zarbock A. Platelets in inflammation and immunity. J Thromb Haemost 2014;12:1764-75.

11 Mangiacapra F, Barbato E. Clinical implications of platelet-vessel interaction. J Cardiovasc Trans/ Res 2013;6:310-5.

12 Payrastre B, Missy K, Trumel C, et al. The integrin $\alpha$ llb/ $\beta 3$ in human platelet signal transduction. Biochem Pharmacol 2000;60:1069-74.

13 Shattil SJ. Signaling through platelet integrin alpha Ilb beta 3: inside-out, outside-in, and sideways. Thromb Haemost 1999;82:318-25.

14 Tamura M, Gu J, Tran H, et al. Pten gene and integrin signaling in cancer. J Nat/ Cancer Inst 1999;91:1820-8.

15 Hynes RO. Integrins: versatility, modulation, and signaling in cell adhesion. Cell 1992;69:11-25.

16 Shattil SJ, Newman PJ. Integrins: dynamic scaffolds for adhesion and signaling in platelets. Blood 2004;104:1606-15.

17 Giancotti FG, Ruoslahti E. Integrin signaling. Science 1999;285:1028-33.

18 Cosemans JMEM, Iserbyt BF, Deckmyn $\mathrm{H}$, et al. Multiple ways to switch platelet integrins on and off. J Thromb Haemost 2008;6:1253-61.

19 Ma Y-Q, Qin J, Plow EF, et al. Platelet integrin alpha(Ilb)beta(3): activation mechanisms. J Thromb Haemost 2007;5:1345-52.

20 Ohta Y, Hartwig JH. Phosphorylation of actin-binding protein 280 by growth factors is mediated by p90 ribosomal protein S6 kinase. J Biol Chem 1996;271:11858-64.

21 Budnik I, Shenkman B, Savion N. Synergistic effect of signaling from receptors of soluble platelet agonists and outside-in signaling in formation of a stable fibrinogen-integrin $\alpha$ llb $\beta 3$-actin cytoskeleton complex. Thromb Res 2015;135:114-20.

22 Litjens PE, Akkerman JW, van Willigen G. Platelet integrin alphallbbeta3: target and generator of signalling. Platelets 2000;11:310-9.

23 Kapur R, Zufferey A, Boilard E, et al. Nouvelle cuisine: platelets served with inflammation. J Immunol 2015;194:5579-87.

24 Speth C, Rambach G, Würzner R, et al. Complement and platelets: mutual interference in the immune network. Mol Immunol 2015;67:108-18.

25 Speth C, Löffler J, Krappmann S, et al. Platelets as immune cells in infectious diseases. Future Microbiol 2013;8:1431-51.

26 Duerschmied D, Bode C, Ahrens I. Immune functions of platelets. Thromb Haemost 2014;112:678-91.

27 Rondina MT, Garraud 0. Emerging evidence for platelets as immune and inflammatory effector cells. Front Immunol 2014;5:653.

28 Gill P, Jindal NL, Jagdis A, et al. Platelets in the immune response: revisiting platelet-activating factor in anaphylaxis. J Allergy Clin Immunol 2015; 135:1424-32.

29 Koike Y, Tanaka K, Kobayashi M, et al. Dynamic pathology for leukocyteplatelet formation in sepsis model. J Surg Res 2015:195:188-95.

30 Angus DC, van der Poll T. Severe sepsis and septic shock. N Engl J Med 2013;369:840-51.

31 Drake TA, Cheng J, Chang A, et al. Expression of tissue factor, thrombomodulin, and E-selectin in baboons with lethal Escherichia coli sepsis. Am J Pathol 1993;142:1458-70

32 McDonald B, Urrutia R, Yipp BG, et al. Intravascular neutrophil extracellular traps capture bacteria from the bloodstream during sepsis. Cell Host Microbe 2012;12:324-33.

$33 \mathrm{Ma}$ AC, Kubes P. Platelets, neutrophils, and neutrophil extracellular traps (NETs) in sepsis. J Thromb Haemost 2008;6:415-20.

34 Tanaka K, Koike Y, Shimura T, et al. In vivo characterization of neutrophil extracellular traps in various organs of a murine sepsis model. PLoS One 2014:9:e111888

35 Akinosoglou K, Alexopoulos D. Use of antiplatelet agents in sepsis: a glimpse into the future. Thromb Res 2014:133:131-8.

36 Carter AM. Complement activation: an emerging player in the pathogenesis of cardiovascular disease. Scientifica 2012;2012:1-14.

37 Zarbock A, Singbartl K, Ley K. Complete reversal of acid-induced acute lung injury by blocking of platelet-neutrophil aggregation. J Clin Invest 2006;116:3211-9.

38 Arthur J, Andrews R, Gardiner E. Neutrophil extracellular traps (NETs) and the role of platelets in infection. Thromb Haemost 2014;112:659-65.

39 Semple JW, Italiano JE, Freedman J. Platelets and the immune continuum. Nat Rev Immunol 2011;11:264-74.

40 Sprague DL, Elzey BD, Crist SA, et al. Platelet-mediated modulation of adaptive immunity: unique delivery of CD154 signal by platelet-derived membrane vesicles. Blood 2008:111:5028-36. 
41 Stearns-Kurosawa DJ, Osuchowski MF, Valentine C, et al. The pathogenesis of sepsis. Annu Rev Pathol 2011;6:19-48.

42 Angus DC, Linde-Zwirble WT, Lidicker J, et al. Epidemiology of severe sepsis in the United States: analysis of incidence, outcome, and associated costs of care. Crit Care Med 2001;29:1303-10.

43 Seeley EJ, Matthay MA, Wolters PJ. Inflection points in sepsis biology: from local defense to systemic organ injury. Am J Physiol Lung Cell Mol Physiol 2012;303:L355-63.

44 Schouten $\mathrm{M}$, Wiersinga WJ, Levi M, et al. Inflammation, endothelium, and coagulation in sepsis. J Leukoc Biol 2008;83:536-45.

45 Levi M, van der Poll T. Inflammation and coagulation. Crit Care Med 2010;38:\$26-34.

46 Semeraro N, Ammollo CT, Semeraro F, et al. Sepsis, thrombosis and organ dysfunction. Thromb Res 2012;129:290-5.

47 Saracco P, Vitale P, Scolfaro C, et al. The coagulopathy in sepsis: significance and implications for treatment. Pediatr Rep 2011;3:e30.

48 de Stoppelaar SF, van 't Veer C, van der Poll T. The role of platelets in sepsis. Thromb Haemost 2014;112:666-77.

49 Mutunga M, Fulton B, Bullock R, et al. Circulating endothelial cells in patients with septic shock. Am J Respir Crit Care Med 2001;163:195-200.

50 Rubenfeld GD, Caldwell E, Peabody E, et al. Incidence and outcomes of acute lung injury. N Engl J Med 2005;353:1685-93.

51 Sigurdsson GH, Christenson JANT, el-Rakshy MB, et al. Intestinal platelet trapping after traumatic and septic shock. An early sign of sepsis and multiorgan failure in critically ill patients? Crit Care Med 1992;20:458-67.

52 Shibazaki M, Kawabata Y, Yokochi T, et al. Complement-dependent accumulation and degradation of platelets in the lung and liver induced by injection of lipopolysaccharides. Infect Immun 1999;67:5186-91.

53 Shibazaki M, Nakamura M, Endo Y, Biphasic EY. Biphasic, organ-specific, and strain-specific accumulation of platelets induced in mice by a lipopolysaccharide from Escherichia coli and its possible involvement in shock. Infect Immun 1996;64:5290-4.

54 Clemetson KJ. Platelets and pathogens. Cell Mol Life Sci 2010;67:495-8.

55 Weyrich AS, Denis MM, Schwertz H, et al. mTOR-dependent synthesis of Bcl-3 controls the retraction of fibrin clots by activated human platelets. Blood 2007;109:1975-83.

56 Weyrich AS, Dixon DA, Pabla R, et al. Signal-dependent translation of a regulatory protein, $\mathrm{BCl}-3$, in activated human platelets. Proc Natl Acad Sci U S A 1998;95:5556-61.

57 Zimmerman GA, Weyrich AS. Signal-dependent protein synthesis by activated platelets: new pathways to altered phenotype and function. Arterioscler Thromb Vasc Biol 2008;28:s17-24.

58 Freishtat RJ, Natale J, Benton AS, et al. Sepsis alters the megakaryocyteplatelet transcriptional axis resulting in granzyme B-mediated lymphotoxicity. Am J Respir Crit Care Med 2009;179:467-73.

59 Wensink AC, Hack CE, Bovenschen N. Granzymes regulate proinflammatory cytokine responses. J Immunol 2015;194:491-7.

60 Chávez-Galán L, Arenas-Del Angel MC, Zenteno E, et al. Cell death mechanisms induced by cytotoxic lymphocytes. Cell Mol Immunol 2009;6:15-25.

61 Voskoboinik I, Whisstock JC, Trapani JA. Perforin and granzymes: function, dysfunction and human pathology. Nat Rev Immunol 2015; 15:388-400.

62 Heutinck KM, ten Berge IJM, Hack CE, et al. Serine proteases of the human immune system in health and disease. Mol Immunol 2010;47:1943-55.

63 Hiebert PR, Granville DJ. Granzyme B in injury, inflammation, and repair. Trends Mol Med 2012;18:732-41

64 Susanto O, Trapani JA, Brasacchio D. Controversies in granzyme biology. Tissue Antigens 2012;80:477-87.

65 Waterhouse NJ, Sedelies KA, Browne KA, et al. A central role for Bid in granzyme B-induced apoptosis. J Biol Chem 2005;280:4476-82.

66 Standage SW, Wong HR. Biomarkers for pediatric sepsis and septic shock. Expert Rev Anti Infect Ther 2011;9:71-9.

67 Sharron M, Hoptay CE, Wiles AA, et al. Platelets induce apoptosis during sepsis in a contact-dependent manner that is inhibited by GPIIb/IIla blockade. PLoS One 2012;7:e41549.

68 Thiagarajan P, Tait JF. Collagen-induced exposure of anionic phospholipid in platelets and platelet-derived microparticles. J Biol Chem 1991;266:24302-7

69 Miyazaki Y, Nomura S, Miyake T, et al. High shear stress can initiate both platelet aggregation and shedding of procoagulant containing microparticles. Blood 1996;88:3456-64

70 Heijnen HFG, Schiel AE, Fijnheer R, et al. Activated platelets release two types of membrane vesicles: microvesicles by surface shedding and exosomes derived from exocytosis of multivesicular bodies and alpha-granules. Blood 1999:94:3791-9.
71 Rendu F, Brohard-Bohn B. The platelet release reaction: granules' constituents, secretion and functions. Platelets 2001;12:261-73.

72 Golebiewska EM, Poole AW. Secrets of platelet exocytosis-what do we really know about platelet secretion mechanisms? Br J Haematol 2014;165:204-16.

73 Ren Q, Ye S, Whiteheart SW. The platelet release reaction: just when you thought platelet secretion was simple. Curr Opin Hematol 2008;15:537-41.

74 Nurden AT, Nurden P. Congenital platelet disorders and understanding of platelet function. Br J Haematol 2014;165:165-78.

75 Italiano JE, Battinelli EM. Selective sorting of alpha-granule proteins.. J Thromb Haemost 2009:7:173-6.

76 Blair P, Flaumenhaft R. Platelet $\alpha$-granules: basic biology and clinical correlates. Blood Rev 2009;23:177-89.

77 Berger G, Masse JM, Cramer EM. Alpha-granule membrane mirrors the platelet plasma membrane and contains the glycoproteins Ib, IX, and V. Blood 1996;87:1385-95

78 McNicol A, Israels SJ. Platelet dense granules: structure, function and implications for haemostasis. Thromb Res 1999;95:1-18.

79 Arraud N, Linares R, Tan S, et al. Extracellular vesicles from blood plasma: determination of their morphology, size, phenotype and concentration. J Thromb Haemost 2014:12:614-27.

80 Jy W, Horstman L, Ahn Y. Microparticle size and its relation to composition, functional activity, and clinical significance. Semin Thromb Hemost 2010;36:876-80

81 Aatonen M, Grönholm M, Siljander P. Platelet-derived microvesicles: multitalented participants in intercellular communication. Semin Thromb Hemost 2012;38:102-13.

82 Théry C, Witwer KW, Aikawa E, et al. Minimal information for studies of extracellular vesicles 2018 (MISEV2018): a position statement of the International Society for extracellular vesicles and update of the MISEV2014 guidelines. J Extracell Vesicles 2018;7.

83 Aatonen MT, Öhman T, Nyman TA, et al. Isolation and characterization of platelet-derived extracellular vesicles. J Extracell Vesicles 2014;3.

84 Johnstone RM, Adam M, Hammond JR, et al. Vesicle formation during reticulocyte maturation. Association of plasma membrane activities with released vesicles (exosomes). J Biol Chem 1987;262:9412-20.

85 Soriano AO, Jy W, Chirinos JA, et al. Levels of endothelial and platelet microparticles and their interactions with leukocytes negatively correlate with organ dysfunction and predict mortality in severe sepsis. Crit Care Med 2005;33:2540-6

86 Bei J-J, Liu C, Peng S, et al. Staphylococcal SSL5-induced platelet microparticles provoke proinflammatory responses via the CD40/ TRAF6/NFkappaB signalling pathway in monocytes. Thromb Haemost 2016;115:632-45

87 Meyer AD, Gelfond JAL, Wiles AA, et al. Platelet-derived microparticles generated by neonatal extracorporeal membrane oxygenation systems. ASAIO J 2015;61:37-42.

88 Ponomareva AA, Nevzorova TA, Mordakhanova ER, et al. Intracellular origin and ultrastructure of platelet-derived microparticles. J Thromb Haemost 2017;15:1655-67.

89 Wang Y, Zhang S, Luo L, et al. Platelet-derived microparticles regulates thrombin generation via phophatidylserine in abdominal sepsis. J Cell Physiol 2018:233:1051-60.

90 Preußer C, Hung L-H, Schneider T, et al. Selective release of circRNAs in platelet-derived extracellular vesicles. J Extrace/l Vesicles 2018;7.

91 Rozmyslowicz T, Majka M, Kijowski J, et al. Platelet- and megakaryocytederived microparticles transfer CXCR4 receptor to CXCR4-null cells and make them susceptible to infection by X4-HIV. AIDS 2003;17:33-42.

92 Hargett LA, Bauer NN. On the origin of microparticles: From "platelet dust" to mediators of intercellular communication. Pulm Circ 2013;3:329-40.

93 Pant S, Hilton H, Burczynski ME. The multifaceted exosome: biogenesis, role in normal and aberrant cellular function, and frontiers for pharmacological and biomarker opportunities. Biochem Pharmacol 2012:83:1484-94.

94 Wang Y, Luo L, Mörgelin M, et al. Rac1 regulates sepsis-induced formation of platelet-derived microparticles and thrombin generation. Biochem Biophys Res Commun 2017;487:887-91

95 Morel O, Morel N, Freyssinet J-M, et al. Platelet microparticles and vascular cells interactions: a checkpoint between the haemostatic and thrombotic responses. Platelets 2008;19:9-23.

96 Owens AP, Mackman N. Microparticles in hemostasis and thrombosis. Circ Res 2011:108:1284-97.

97 Alexandru N, Andrei E, Dragan E, et al. Interaction of platelets with endothelial progenitor cells in the experimental atherosclerosis: role of transplanted endothelial progenitor cells and platelet microparticles. Biol. Cell 2015:107:189-204. 
98 Berckmans RJ, Nieuwland R, Böing AN, et al. Cell-derived microparticles circulate in healthy humans and support low grade thrombin generation. Thromb Haemost 2001;85:639-46.

99 Boilard E, Nigrovic PA, Larabee K, et al. Platelets amplify inflammation in arthritis via collagen-dependent microparticle production. Science 2010;327:580-3.

100 Dinkla S, van Cranenbroek B, van der Heijden WA, et al. Platelet microparticles inhibit IL-17 production by regulatory $T$ cells through P-selectin. Blood 2016;127:1976-86.

101 Nomura S, Okamae F, Abe M, et al. Platelets expressing P-selectin and platelet-derived microparticles in stored platelet concentrates bind to PSGL-1 on filtrated leukocytes. Clin App/ Thromb Hemost 2000;6:213-21.

102 Sibikova M, Zivny J, Janota J. Cell membrane-derived microvesicles in systemic inflammatory response. Folia Biol 2018;64:113-24.

103 Barry OP, Kazanietz MG, Praticò D, et al. Arachidonic acid in platelet microparticles up-regulates cyclooxygenase-2-dependent prostaglandin formation via a protein kinase C/mitogen-activated protein kinase-dependent pathway. J Biol Chem 1999;274:7545-56.

104 Brown GT, Mclntyre TM. Lipopolysaccharide signaling without a nucleus: kinase cascades stimulate platelet shedding of proinflammatory IL-1beta-rich microparticles. J Immunol 2011;186:5489-96.

105 Woth G, Tőkés-Füzesi M, Magyarlaki T, et al. Activated platelet-derived microparticle numbers are elevated in patients with severe fungal (Candida albicans) sepsis. Ann Clin Biochem 2012;49:554-60.

106 Øvstebø R, Hellum M, Aass HCD, et al. Microparticle-associated tissue factor activity is reduced by inhibition of the complement protein 5 in Neisseria meningitidis-exposed whole blood. Innate Immun 2014;20:552-60.

107 Boilard E, Paré G, Rousseau M, et al. Influenza virus H1N1 activates platelets through FcgammaRIIA signaling and thrombin generation. Blood 2014;123:2854-63.
108 Sung P-S, Huang T-F, Hsieh S-L. Extracellular vesicles from CLEC2-activated platelets enhance dengue virus-induced lethality via CLEC5A/TLR2. Nat Commun 2019;10:2402.

109 Punyadee N, Mairiang D, Thiemmeca S, et al. Microparticles provide a novel biomarker to predict severe clinical outcomes of dengue virus infection. J Virol 2015;89:1587-607.

110 Patil R, Bajpai S, Ghosh K, et al. Microparticles as prognostic biomarkers in dengue virus infection. Acta Trop 2018;181:21-4.

111 Asfari A, Dent JA, Corken A, et al. Platelet glycoprotein VI haplotypes and the presentation of paediatric sepsis. Thromb Haemost 2019;119:431-8.

112 Puskarich MA, Cornelius DC, Bandyopadhyay S, et al. Phosphatidylserine expressing platelet microparticle levels at hospital presentation are decreased in sepsis non-survivors and correlate with thrombocytopenia. Thromb Res 2018;168:138-44.

113 Boscolo A, Campello E, Bertini D, et al. Levels of circulating microparticles in septic shock and sepsis-related complications: a case-control study. Minerva Anestesiol 2019;85:625-34.

114 Janiszewski M, Do Carmo AO, Pedro MA, et al. Platelet-derived exosomes of septic individuals possess proapoptotic NAD(P)H oxidase activity: A novel vascular redox pathway. Crit Care Med 2004;32:818-25.

115 Gambim MH, do Carmo AdeO, Marti L, et al. Platelet-derived exosomes induce endothelial cell apoptosis through peroxynitrite generation: experimental evidence for a novel mechanism of septic vascular dysfunction. Crit Care 2007;11.

116 Azevedo LCP, Janiszewski M, Pontieri V, et al. Platelet-derived exosomes from septic shock patients induce myocardial dysfunction. Crit Care 2007;11.

117 Monteiro VVS, Reis JF, de Souza Gomes R, et al. Dual behavior of exosomes in septic cardiomyopathy. Adv Exp Med Biol 2017;998:101-12. 